\title{
On the Lithium Distribution in Halide Superionic Argyrodites by Halide Incorporation in $\mathrm{Li}_{7-\mathrm{x}} \mathbf{P S}_{6-\mathrm{x}} \mathrm{Cl}_{\mathrm{x}}$
}

\author{
Ajay Gautama, Michael Ghidiu ${ }^{\mathrm{a}}$, Emmanuelle Suard ${ }^{\mathrm{b}}$, Marvin A. Kraft ${ }^{\mathrm{c}}$, \\ Wolfgang G. Zeier*c,d \\ anstitute of Physical Chemistry, Justus-Liebig-University Giessen, Heinrich-Buff-Ring \\ 17, D-35392 Giessen, Germany. \\ ${ }^{b}$ Institut Laue-Langevin, 71 avenue des Martyrs, 38042 Grenoble, Cedex 9 - France \\ 'Institute of Inorganic and Analytical Chemistry, University of Münster, Corrensstrasse 30, \\ 48149 Münster, Germany \\ ${ }^{d}$ Helmholtz Institute Münster (IEK-12), Forschungszentrum Jülich GmbH, \\ Corrensstrasse 46, 48149 Münster, Germany
}

\section{E-mail:}

*wzeier@uni-muenster.de

\begin{abstract}
Superionic lithium argyrodites are attractive as solid electrolytes for all-solid-state-batteries. These materials of composition $\mathrm{Li}_{6} \mathrm{PS}_{5} \mathrm{X}(\mathrm{X}=\mathrm{Cl}, \mathrm{Br}$, and $\mathrm{I})$ exhibit structural disorder between the $\mathrm{X}^{-} / \mathrm{S}^{2-}$ positions, with higher disorder realizing better $\mathrm{Li}^{+}$transport. Further replacement of the sulfide by chloride anions (for the series $\mathrm{Li}_{7-\mathrm{x}} \mathrm{PS}_{6-\mathrm{x}} \mathrm{Cl}_{\mathrm{x}}$ ) has been shown to increase the ionic conductivity. However, the underlying changes to the lithium substructure are still relatively unknown. Here we explore a larger range of nominal halide compositions in this material from $\mathrm{x}=0.25$ to $\mathrm{x}=1.5$ and explore the changes with neutron diffraction and impedance spectroscopy. The replacement of $\mathrm{S}^{2-}$ by $\mathrm{Cl}^{-}$causes a lowered average charge in the center of the prevalent $\mathrm{Li}^{+}$"cages", which in turn causes weaker interactions with $\mathrm{Li}^{+}$ions. Analysis of neutron diffraction data reveals that the increased $\mathrm{Cl}^{-}$content causes these clustered $\mathrm{Li}^{+}$"cages" to become more interconnected, thereby increasing $\mathrm{Li}^{+}$conductivity through the structure. This study explores the understanding of the fundamental structure-transport correlations in the argyrodites, specifically structural changes within the $\mathrm{Li}^{+}$ion substructure upon changing anionic charge distribution.
\end{abstract}




\section{Introduction}

All-solid-state-batteries are attracting significant interest for next-generation lithium-ion batteries due to their device safety and improved energy density, as well as wider operating temperatures compared to conventional lithium-ion batteries. ${ }^{1-5}$ Solid electrolytes typically used for solid state batteries are oxides ${ }^{6,7}$ phosphates, ${ }^{8,9}$ lithium-based halides ${ }^{10-13}$ and lithium thiophosphates ${ }^{14-16}$; among all of them, thiophosphates are promising candidates for solid-state batteries because of their high ionic conductivity and mechanical softness. ${ }^{2,17,18}$ The lithium argyrodites $\mathrm{Li}_{6} \mathrm{PS}_{5} \mathrm{X}(\mathrm{X}=$ $\mathrm{Cl}, \mathrm{Br}, \mathrm{I})$ especially are gaining more attention. ${ }^{19,20}$ This is to a large extent due to the fact that elemental substitution and changing synthetic approaches have shown to improve the ionic conductivity of these materials, ${ }^{21-25}$ which makes the fabrication of solid state batteries with thick electrodes improving the energy densities of all-solid-state-batteries.

Considering the halide-containing argyrodites $\mathrm{Li}_{6_{-} \mathrm{x}} \mathrm{PS}_{5_{-\mathrm{x}}}(\mathrm{Cl}, \mathrm{Br}, \mathrm{I})_{1+\mathrm{x}},{ }^{19,26}$ these can be thought of as derivatives from the simple $\mathrm{Li}_{7} \mathrm{PS}_{6}$; this otherwise orthorhombic material can only be found in its superionic cubic polymorph above $210^{\circ} \mathrm{C} .{ }^{27,28}$ The structure of $\mathrm{Li}_{7} \mathrm{PS}_{6}$ consists of $\mathrm{PS}_{4}{ }^{3-}$ tetrahedra and unbound $\mathrm{S}^{2-}$ anions; in the halogen-substituted phases, the halide $X$ takes the place of some of these 'free' sulfide anions and stabilizes the cubic polymorph at room temperature. The cubic $\mathrm{Li}_{6} \mathrm{PS}_{5} \mathrm{Cl}$ is shown in Figure 1a, with the halide anion $\mathrm{X}^{-}$located in a cubic close-packed lattice (Wyckoff $4 a$ ). $\mathrm{P}$ is bonded to four ions forming $\mathrm{PS}_{4}{ }^{3-}$ polyhedra in which the $\mathrm{P}$ center occupies the octahedral sites ( $P$ and $S$ occupy the $4 b$ and $16 e$ Wyckoff position). 'Free' $\mathrm{S}^{2-}$ ions occupy half of the tetrahedral sites (Wyckoff $4 d$ ). Analogous to the other halide argyrodite structures, the lithium ions occupy a number of different sites shown in (Figure 1b), so-called T5 (Wyckoff 48h), and T2 (Wyckoff 48h) to form a cage-like arrangement around the $4 d$ sites; recent publications have identified the possible diffusion pathway through the argyrodite structure mostly involving the T2 - T2 distance as the main connecting step from the cage to cage, shown in Figure 1c. ${ }^{29,30}$ Differences in the $\mathrm{Li}^{+}$positions, the Li substructure, has recently been well summarized by calculating the radial distribution of $\mathrm{Li}^{+}$around the $4 d$ site, and determining the radius where the mean amount of Li sits, designated as $R_{\text {mean. }}{ }^{26,29}$ Importantly, depending on composition and treatment history, ${ }^{26,29,31}$ the halide nominally on $4 a$ and the sulfide on $4 d$ can exchange positions, leading to site-disorder. This has been invoked as a key factor in changing unit cell volume as well as transport properties. ${ }^{24-26,29,32,33}$ Site-disorder has been shown to affect the lithium substructure 
by modifying the $\mathrm{Li}^{+}$site locations and occupancies, and in turn changing $R_{\text {mean }}$. A reason for some of these effects is the changing average site charge on $4 a$ and $4 d$ because of the electrostatic difference between $\mathrm{S}^{2-}$ and $X^{-}{ }^{29,30}$
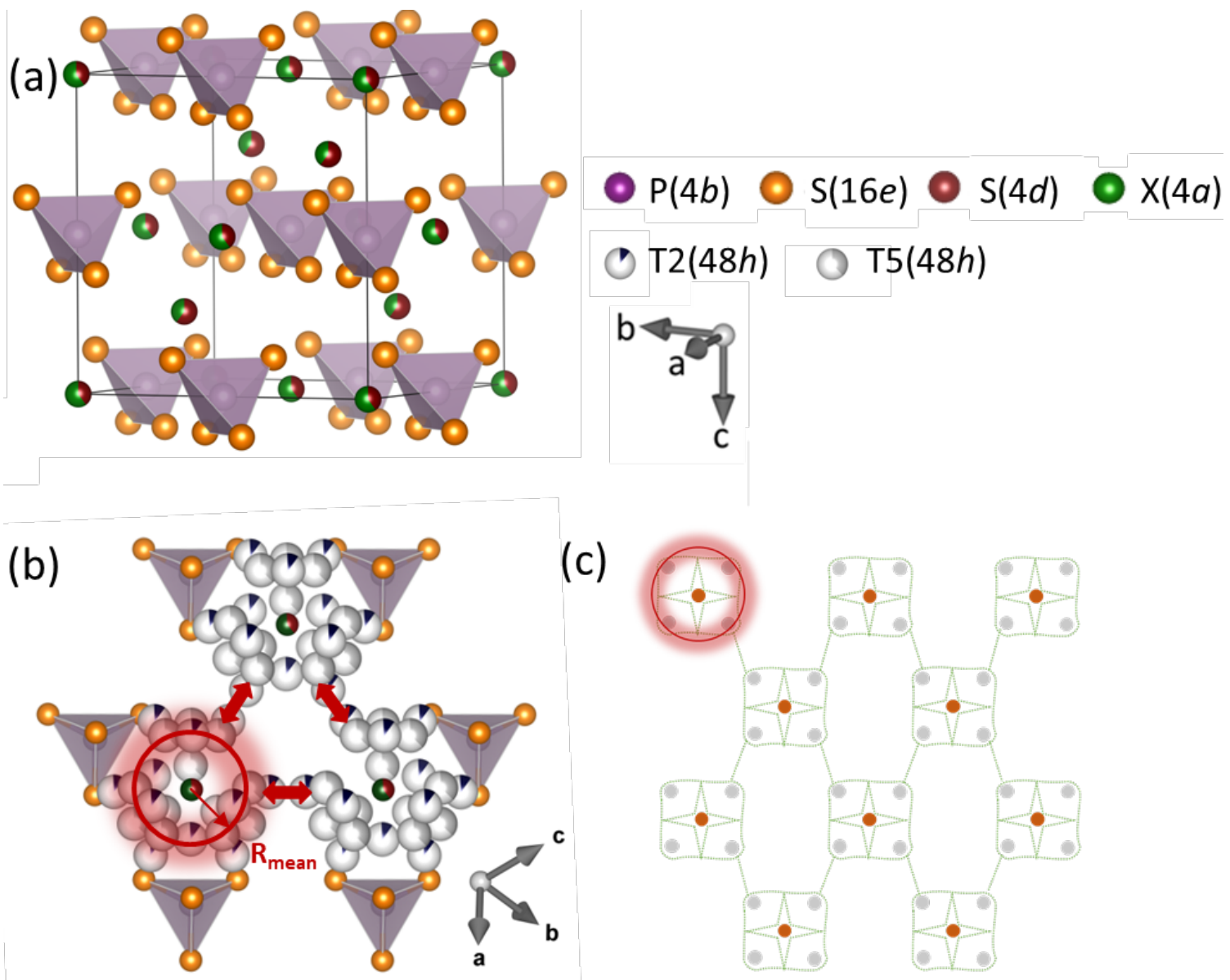

(c)

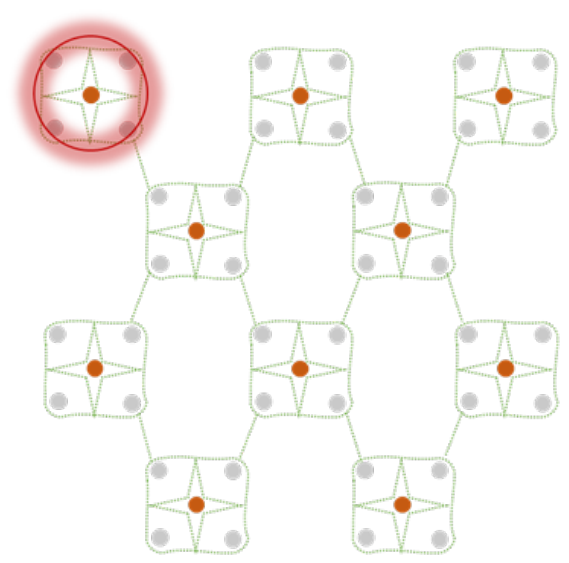

Figure 1: a) Crystal structure of $\mathrm{Li}_{6} \mathrm{PS}_{5} \mathrm{Cl}$ shown in anion site-disordered state with $40 \% \mathrm{Cl}^{-}$ located on the Wyckoff $4 a$ site and the $40 \%$ sulfide anion $\left(S^{2-}\right)$ on the Wyckoff $4 d$ site. b) Lithium substructure in $\mathrm{Li}_{6} \mathrm{PS} \mathrm{S}_{5} \mathrm{Cl}$ argyrodites, showing $\mathrm{T5}$ (Wyckoff 48h), T2 (Wyckoff 48h) sites to coordinate around an $S^{2-}$ central anion on the Wyckoff $4 d$ site. T2 - T2 offer the shortest intercage jump distance ("red arrows"). The average radial distribution of Li away from the Wyckoff $4 d$ central anion is described by $R_{\text {mean. }}$ c) Visual representation of the Li connectivity in which the T2 - T2 jump offers the shortest distance at a larger $R_{\text {mean }}$.

It has been shown that the different type of halide ion can influence ionic transport and whether and to what extent disordering occurs. ${ }^{19}$ While iodide versions exhibit virtually no sitedisordering, ${ }^{26}$ chloride substitutions seem to encourage the highest amount of site-disorder and the 
highest conductivities. ${ }^{19,26}$ With the multiple 'free' anion sites, from a starting point of $\mathrm{Li}_{7} \mathrm{PS}_{6}$ and a full chloride occupancy endpoint of $\mathrm{Li}_{5} \mathrm{PS}_{4} \mathrm{Cl}_{2}$ (full replacement of $\mathrm{S}^{2-}$ anions), there is a wide compositional space in $\mathrm{Li}_{7-\mathrm{x}} \mathrm{PS}_{6-\mathrm{x}} \mathrm{X}_{\mathrm{x}}(\mathrm{X}=\mathrm{Cl}, \mathrm{Br}, \mathrm{I})$ to explore, given the potential for anionic sitedisordering and changing Li carrier density. ${ }^{25}$ Nazar et al. recently showed the substitution series $\mathrm{Li}_{7-\mathrm{x}} \mathrm{PS}_{6-\mathrm{x}} \mathrm{Cl}_{\mathrm{x}}\left(x \leq 0.5\right.$; functionally equivalent to $\mathrm{Li}_{7-\mathrm{x}} \mathrm{PS}_{6-\mathrm{x}} \mathrm{Cl}_{\mathrm{x}}$ with an offset in $x$ of unity) with a conductivity of $9 \mathrm{mS} \mathrm{cm}{ }^{-1}$ achieved at $x=0.5$ (measured as $x=0.45$ ). ${ }^{33}$ In addition to increasing halide, Hu et al. reported the $\mathrm{Br}$ substitution series $\mathrm{Li}_{6-\mathrm{x}} \mathrm{PS}_{5-\mathrm{x}} \mathrm{Br}_{1+\mathrm{x}}(x \leq 0.7)$ in which a $10 \mathrm{mS} \mathrm{cm}^{-1}$ conductivity was achieved for sintered $\mathrm{Li}_{5.3} \mathrm{PS}_{4.3} \mathrm{Br}_{1.7}{ }^{34}$ The conductivities of these phases are an improvement over the 'standard' composition at $x=0, \mathrm{Li}_{6} \mathrm{PS}{ }_{5} \mathrm{Cl} / \mathrm{Br}$, so clearly they are of interest. However, what is missing is an expansion of the range of $x$ to include compositions closer to $\mathrm{Li}_{6.75} \mathrm{PS}_{5.75} \mathrm{Cl}_{0.25}$ and a full structural study of the changing $\mathrm{Li}^{+}$substructure, and how it relates to changes in transport. This will lead to a more fundamental understanding of how these substructures play a role in optimizing conductivity outside the more oft-studied composition of $\mathrm{Li}_{6} \mathrm{PS}_{5} \mathrm{X}$.

In this work, we explore the entire compositional space of $\mathrm{Li}_{7-\mathrm{x}} \mathrm{PS}_{6-\mathrm{x}} \mathrm{Cl}_{\mathrm{x}}$, across a range of $(0.25 \leq$ $x \leq 1.5$ ). With this series we are able to perform neutron diffraction to characterize how the lithium substructure changes. This helps gain a deeper understanding of why conductivities are so strongly affected by changes in $\mathrm{Cl}$ content. With increases in $\mathrm{Cl}$, disorder on the $4 d$ site increases, as well as the expansion of "cages" of $\mathrm{Li}^{+}$around the site, all of which seems to be beneficial to the ionic transport. 


\section{Experimental Section}

Synthesis. All synthesis work and sample treatment for $\mathrm{Li}_{7-\mathrm{x}} \mathrm{PS}_{6-\mathrm{x}} \mathrm{Cl}_{\mathrm{x}}$ was performed under an argon atmosphere $\left(\mathrm{O}_{2}<1 \mathrm{ppm}\right.$ and $\left.\mathrm{H}_{2} \mathrm{O}<1 \mathrm{ppm}\right)$. Lithium sulfide ( $\mathrm{Li}_{2} \mathrm{~S}$, Alfa-Aesar, 99.9\%), phosphorus pentasulfide ( $\mathrm{P}_{4} \mathrm{~S}_{10}$, Merck, 99\%), and lithium chloride ( $\mathrm{LiCl}$, Alfa Aesar, 99.9\%) were mixed to obtain $3 \mathrm{~g}$ batches of the precursor. The obtained precursor was put into a $45 \mathrm{ml}$ ball milling cup using a 40:1 mass ratio of milling media to precursors ( $5 \mathrm{~mm}$ diameter zirconia milling balls, Fritsch Pulverisette 7 premium line). The precursors were then milled for a total of 60 cycles, each with 10 minutes of milling time followed by 10 minutes of rest. After every 20 cycles, the ball milling cups were opened inside the glovebox to dislodge material adhered to the milling cup inside surfaces. The completely milled material was then manually hand pressed into pellets and filled into $\sim 8 \mathrm{~cm}$ long quartz ampoules $\left(10 \mathrm{~mm}\right.$ inner diameter, first heat treated at $800{ }^{\circ} \mathrm{C}$ under a dynamic vacuum for 2 hours to remove all traces of water). The quartz ampoules were sealed under static vacuum. For crystallization, the ampoules were inserted into a tube furnace and heated to specific temperatures: $550^{\circ} \mathrm{C}$ for $x \leq 1.0$, and $450^{\circ} \mathrm{C}$ for $1.25 \leq x \leq 1.75$ (ramping rate of 100 ${ }^{\circ} \mathrm{C}$ per hour followed by 2 hours dwell time, then natural cooling. This reaction time served to ensure the complete formation of argyrodites. The final product was hand-ground into a powder for neutron diffraction studies and pressed into the cell for electrochemical measurements.

Neutron powder diffraction. The neutron powder diffraction data were collected on the D2B highresolution powder diffractometer at the Institute Laue-Langevin (ILL, Grenoble, France), with incident monochromatic wavelength $\lambda=1.594 \AA$. Starting point scan was repeated several times at various $10^{\circ}<2 \theta \leq 160^{\circ}$ values to improve statistics, and each data collection required 4 hours.

Rietveld Analysis. Rietveld refinements were performed using the TOPAS-Academic V6 software package. Initially, the structural information obtained from the neutron refinement of $\mathrm{Li}_{6} \mathrm{PS}_{5} \mathrm{Cl}$ from Minafra et al. was used. ${ }^{26}$ These steps were used during the refinements: (1) scale factor, (2) 10 coefficients for a Chebyshev function background, (3) peak shape parameters, (4) lattice parameters, (5) zero error, (6) fractional atomic coordinates, (7) atomic occupancies and finally (8) isotropic atomic displacement parameters. Then multiple correlated parameters were refined simultaneously and constraints table can be found separately in Table S1. 
Bond Valence Sum Analysis. The bond valence sum analysis was carried out using the softBV software tool combine with grid size of $0.1 \AA$. Initially the crystallographic information file extracted from the neutron diffraction data was used to obtain the energy landscape. ${ }^{35}$ The BVS models were used for finding the transport pathway. More details of the BVS model can be found in ref 35 .

Electrochemical Impedance spectroscopy. The ionic conductivities were measured using AC impedance spectroscopy. A steel press-cell was used for all impedance measurements following previous work. ${ }^{36}$ All compositions were pressed uniaxially with a pressure of $382 \mathrm{MPa}$ for 3 minutes. The resulting densities of the pellets were $\sim 81 \%$. All Electrochemical impedance spectroscopy (EIS) measurements were performed using a VMP300 impedance analyzer (Biologic) with a frequency range of $7 \mathrm{MHz}$ to $100 \mathrm{mHz}$ with an amplitude of $10 \mathrm{mV}$ in a temperature range of $-40{ }^{\circ} \mathrm{C}$ to $60^{\circ} \mathrm{C}$. The analyses of obtained spectra were performed using the RelaxIS 3 Impedance Spectrum Analysis software (RHD instruments, Darmstadt, Germany). 


\section{Results and Discussion}

Structural changes. Mechanochemical synthesis was used to synthesize the series $\mathrm{Li}_{7-\mathrm{x}} \mathrm{PS}_{6-\mathrm{x}} \mathrm{Cl}_{\mathrm{x}}(0$ $\leq x \leq 1.75$ ) and to study how changes in transport properties can be understood through changes to the crystal structure and $\mathrm{Li}^{+}$substructure. The precursors $\mathrm{Li}_{2} \mathrm{~S}, \mathrm{P}_{4} \mathrm{~S}_{10}$, and $\mathrm{LiCl}$ were mechanically milled to achieve uniform mixing. For subsequent crystallization, these compositions needed to be heated at different temperatures, with $550{ }^{\circ} \mathrm{C}$ for samples $x=0.0$ to 1.00 , or at a reduced temperature of $450^{\circ} \mathrm{C}$ (for samples $x=1.25,1.50$ and 1.75). For the structural characterization, neutron diffraction was carried out, and the obtained patterns were analyzed using Rietveld refinements. Figure $2 \mathrm{a}$ shows a refinement of $\mathrm{Li}_{5.5} \mathrm{PS}_{4.5} \mathrm{Cl}_{1.5}$ as an example; all refinements and the tabulated structural information can be found in the Supporting Information, Figures S1-S6, and Tables S2-S7.
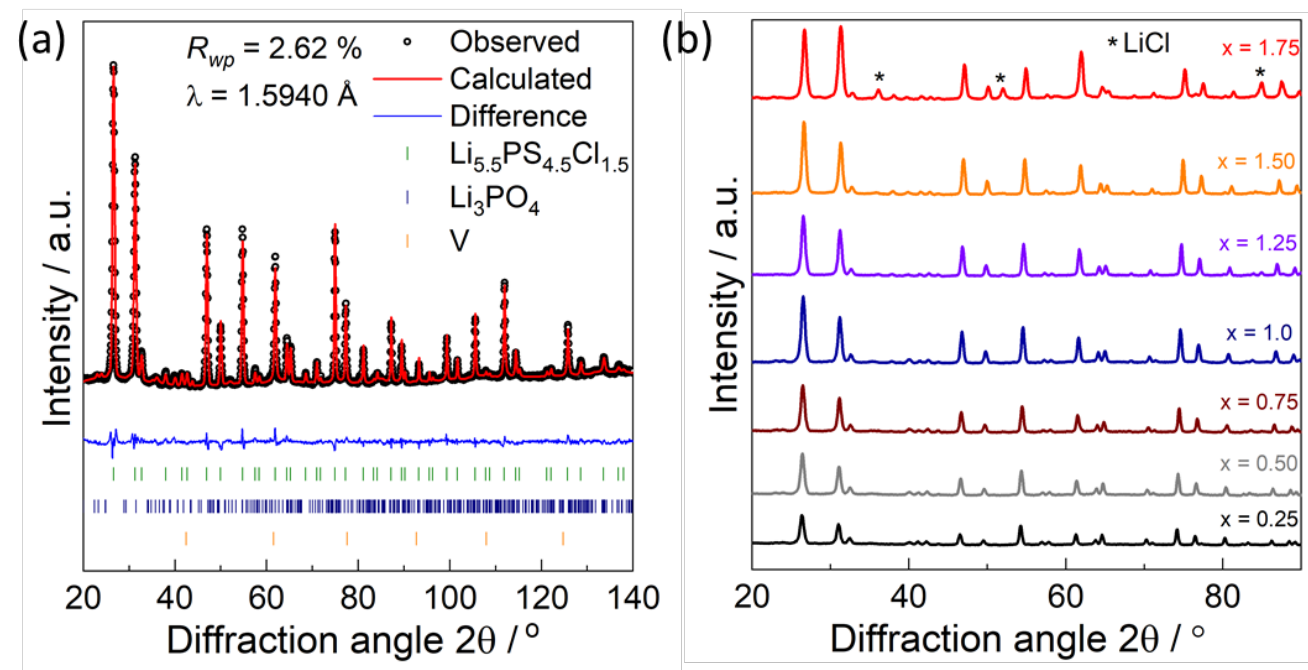

Figure 2: a) Representative Rietveld refinement against neutron diffraction data of $L_{i 5.5} P S_{4.5} C_{1.5}$. A small fraction of impurity phases corresponding to $\sim 0.7 \mathrm{wt} \% \mathrm{Li}_{3} \mathrm{PO}_{4}$ is present, along with reflections from the vanadium sample container. b) Stacked neutron diffraction patterns of the synthesized materials with different chloride content $x$ of for $\mathrm{Li}_{7-x} P S_{6-x} C l_{x}$.

All samples (compiled in Figure $2 \mathrm{~b}$ ) exhibited minor impurity phases of $\mathrm{Li}_{3} \mathrm{PO}_{4}$ (no more than 2.0 $\mathrm{wt} \%)$. The composition of $\mathrm{x}=0$, i.e. $\mathrm{Li}_{7} \mathrm{PS}_{6}$ was analyzed using Rietveld refinements against $\mathrm{X}$ ray diffraction data only. The known orthorhombic phase (shown in Figure S7) can be observed. By increasing the halide content to $x=0.25$, the orthorhombic structure changes to the cubic polymorph. By further increasing the halide content, the amount of $\mathrm{LiCl}$ impurity increases, and 
in $x=1.75$ compositions around $10 \mathrm{wt} \% \mathrm{LiCl}$ is present (together with $\sim 3 \mathrm{wt} \% \mathrm{Li}_{3} \mathrm{PS}_{4}$ ), indicating that a solubility limit has been reached. This is in agreement with the findings of Nazar and coworkers. ${ }^{33}$ For the following analyses only the cubic polymorphs that have not reached the solubility limit yet, i.e. $\mathrm{Li}_{7-\mathrm{x}} \mathrm{PS}_{6-\mathrm{x}} \mathrm{Cl}_{\mathrm{x}}(0.25 \leq x \leq 1.50)$, were are investigated using neutron diffraction.
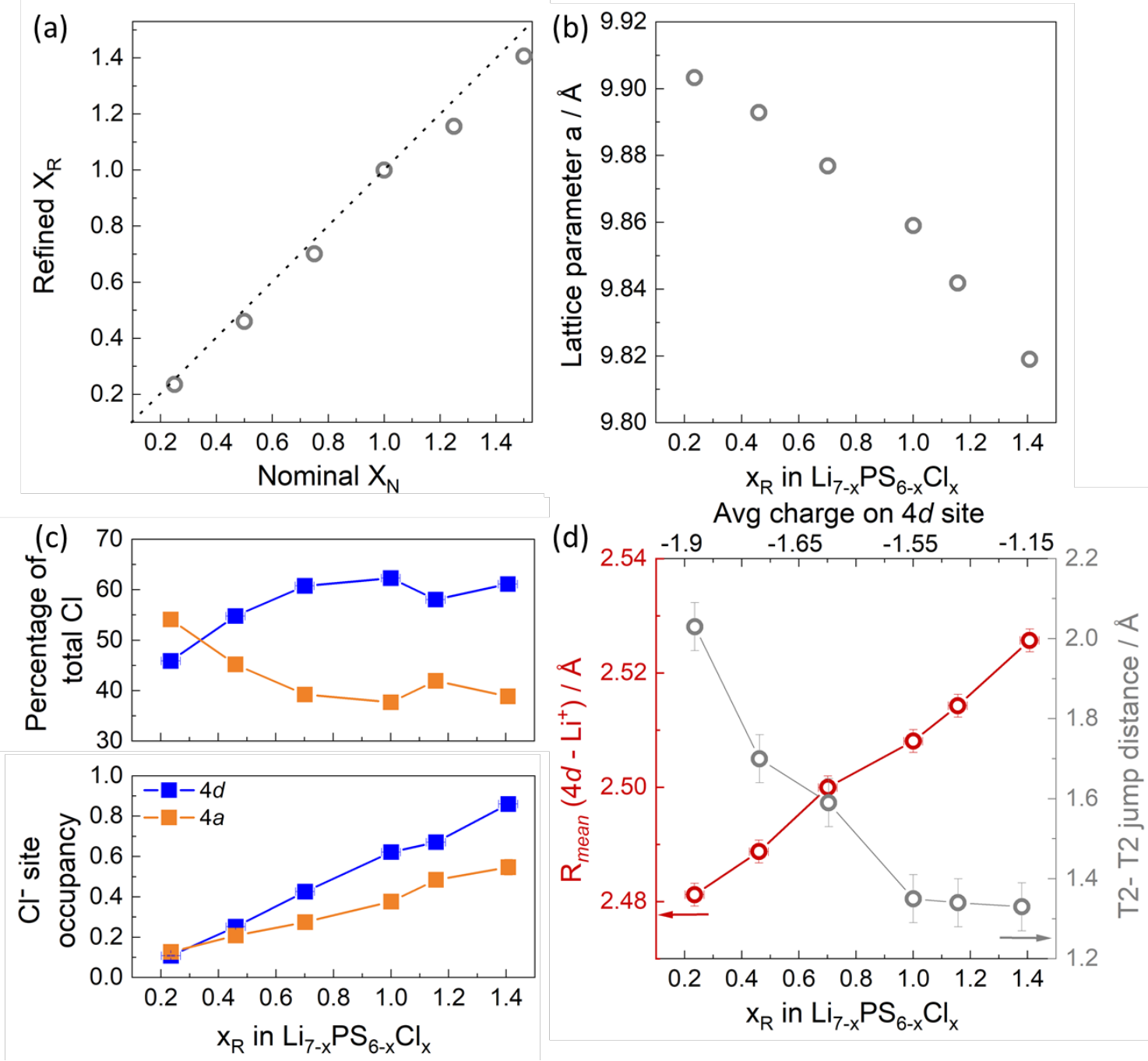

Figure 3: a) A comparison of nominal contents of chloride with refined chloride contents in $\mathrm{Li7-x}_{7-x} P S_{6-x} C l_{x}$. Idealized ratio given as dashed line. b) The lattice parameter decreases as the chloride content increases. c) Top panel shows the percentage of total $\mathrm{Cl}$ content distributed across each of the two Wyckoff sites, and bottom panel shows the Cl occupancy of the sites as it increases with increasing $C l$ content. d) $R_{\text {mean }}$, representing the radial distance between the centers 
of the cage (Wyckoff $4 d)$ and the mean Li density of the surrounding cage, increases, and the T2T2 distance (inter-cage jump) significantly decreases with increasing $\mathrm{Cl}$ content.

The nominal contents $\left(\mathrm{x}_{\mathrm{N}}\right)$ of chloride used for the synthesis $\left(\mathrm{Li}_{7-\mathrm{x}} \mathrm{PS}_{6_{-\mathrm{x}}} \mathrm{Cl}_{\mathrm{x}}\right)$ and refined contents $\left(x_{R}\right)$ of chloride extracted from the refinement of neutron diffraction data are shown in Figure 3a, indicating that not all of the $\mathrm{Cl}^{-}$available is taken up at higher $x$. This is consistent with the observed solubility limit at higher $\mathrm{Cl}^{-}$fractions. The increasing chloride content causes the lattice parameter to decrease (Figure 3b); the kink in the linearity of the lattice parameter decrease is reflected in the deviation in the solubility. The changing lattice volume might not be expected given the similar ionic radii between $\mathrm{Cl}^{-}(167 \mathrm{pm})$ and $\mathrm{S}^{2-}(170 \mathrm{pm})$. One possibility is that the $\mathrm{Li}^{+}$vacancies caused by the replacement of divalent sulfide with monovalent chloride may play a role in the decrease of the lattice parameter. A second possibility may be the site-disorder of $\mathrm{X}^{-} / \mathrm{S}^{2-}$ that has also been shown previously to have an effect on lattice parameter, even at fixed composition. ${ }^{19,29,33}$ Nevertheless, chloride added into the structure (increasing $x$ ) distributes across the Wyckoff $4 a$ and $4 d$ sites (Figure 3c, bottom panel). A site-disorder in terms of simple occupancy of $4 d$ cannot be established with changing $\mathrm{Cl}^{-}$content, so instead, of the total amount of $\mathrm{Cl}^{-}$from the refined $\mathrm{x}_{\mathrm{R}}$ values, the percentage of this amount that sits on each respective Wyckoff site is shown in Figure 3c, top panel. This gives an idea of how the distribution across the two sites changes from a disorder at the nominal composition $\mathrm{Li}_{6} \mathrm{PS}_{5} \mathrm{Cl}$ of $62.3(0.7) \%$. It is clear that it is not constant and that preference seems to change from $4 a$ to $4 d$, as more $\mathrm{Cl}^{-}$is added. The lithium occupancy in different lithium positions can be found in Figure S8. Due to the charge difference of $\mathrm{Cl}^{-}$and $\mathrm{S}^{2-}$, the average charge on the Wyckoff $4 a$ and $4 d$ sites will change based on its occupancy. As a direct result of the changing local charge environment, the average surrounding $\mathrm{Li}^{+}$substructure is expected to change. $\mathrm{Li}^{+}$positions can be directly extracted from the neutron diffraction results. In order to better conceptualize how the substructure changes with chloride content, we have applied the same analysis from Minafra et al. reported on the lithium argyrodite sublattice of $\mathrm{Li}_{6} \mathrm{PS}_{5} \mathrm{X}(\mathrm{X}=\mathrm{Cl}, \mathrm{Br}, \mathrm{I})^{26}$ and recent work on $\mathrm{Li}_{6} \mathrm{PS}_{5} \mathrm{Br}$ with changing $\mathrm{S}^{2-} / \mathrm{Br}^{-}$site disorder ${ }^{29}$ From the refined crystallographic data, the $\mathrm{Li}^{+}$distribution is determined radially from the $4 d$ site (the center of the $\mathrm{Li}^{+}$"cage"). ${ }^{26}$ The radius at which the mean $\mathrm{Li}^{+}$density is located is denoted as $R_{\text {mean }}$. A higher value of $R_{\text {mean }}$ describes an expansion of the $\mathrm{Li}^{+}$"cage" away from its center, and to a point, a higher level of interconnectivity of the cages.$^{29}$ The effect of increasing the chloride content $x$ is to increase $R_{\text {mean }}$, from a value of $2.475 \AA$ in $\mathrm{x}_{\mathrm{R}}=0.235$ to $2.525 \AA$ in 
$\mathrm{X}_{\mathrm{R}}=1.40$. The $\mathrm{T} 2-\mathrm{T} 2$ distance represents the shortest path between $\mathrm{Li}^{+}$positions of separate lithium cages; this has been invoked in the past as a critical point for improving transport, as the cages must be interconnected for three-dimensional $\mathrm{Li}^{+}$movement in the bulk. ${ }^{26,29}$ The change in T2 - T2 distance is shown in Figure 3d; with increasing chloride content, the distance decreases which is expected to lead to an higher bulk $\mathrm{Li}^{+}$mobility. However, as discussed in our previous work, ${ }^{26,29}$ we believe that $R_{\text {mean }}$ is a better general descriptor of the phenomenon. For the following sections, transport is described in terms of this parameter.

Ionic transport properties. Temperature-dependent electrochemical impedance spectroscopy was performed to determine the ionic conductivity of the chloride enriched lithium argyrodites $\mathrm{Li}_{7-x} \mathrm{PS}_{6-\mathrm{x}} \mathrm{Cl}_{\mathrm{x}}$ up to $\mathrm{x}=1.50$. Exemplarily shown for the Nyquist plots of the nominal composition $\mathrm{x}_{\mathrm{N}}=1.00,1.25$, and 1.50 at $-30{ }^{\circ} \mathrm{C}$ in Figure $4 \mathrm{a}$, the data can be fit with an equivalent circuit model of a resistor element in parallel with a constant phase element (CPE), in series with another constant phase element corresponding to the materials resistance and electrode blocking behavior, respectively. All remaining temperature - dependent impedance data can be found in the Figure S9.
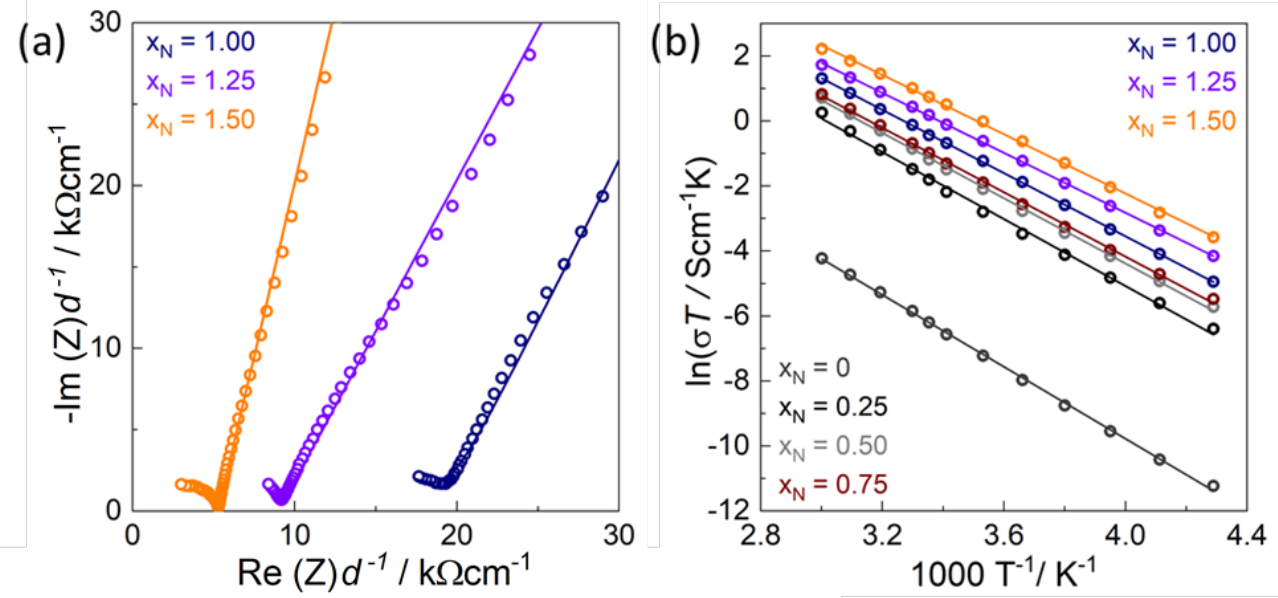

Figure 4: a) Representative fit of the impedance spectra of $\mathrm{Li}_{7-x} P S_{6-x} \mathrm{Cl}_{x}$ as a function of different nominal chloride compositions; the impedance is shown normalized by the pellet thickness for comparison. b) Representative Arrhenius data of the solid solutions.

The impedance spectra at lower temperatures show suppressed semicircles and a capacitive blocking behavior of the electrodes. The obtained capacitances of the high frequency process are $2.2-9.0 \cdot 10^{-10} \mathrm{~F}$ with ideality factors of $\alpha>0.85$. At higher temperature, the contribution of the 
resistor/CPE shifts to frequencies that are too high to resolve within the probed frequency range and only the tail of the blocking electrode behavior was used for impedance fitting as shown in Figure S9. Clearly, the bulk and grain boundary contributions cannot be deconvoluted and all values represent total ionic conductivities. The temperature dependent ionic conductivities for all compositions are shown in Figure 4b, showing linear Arrhenius behavior as expected.

(a)

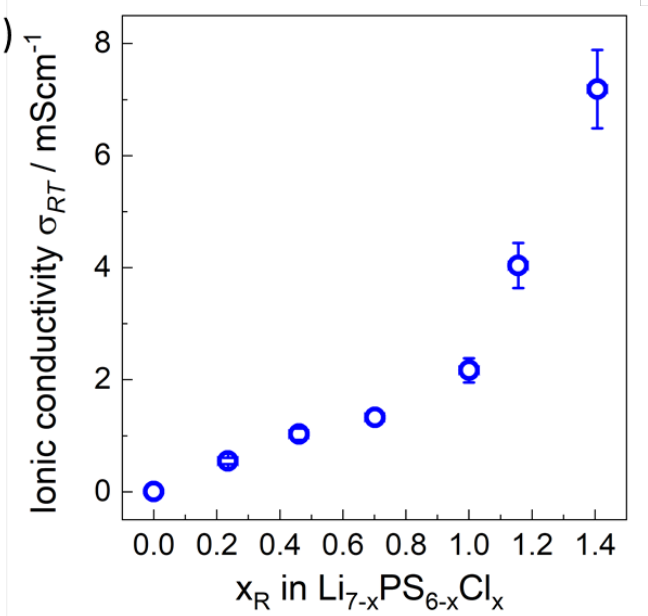

(c)

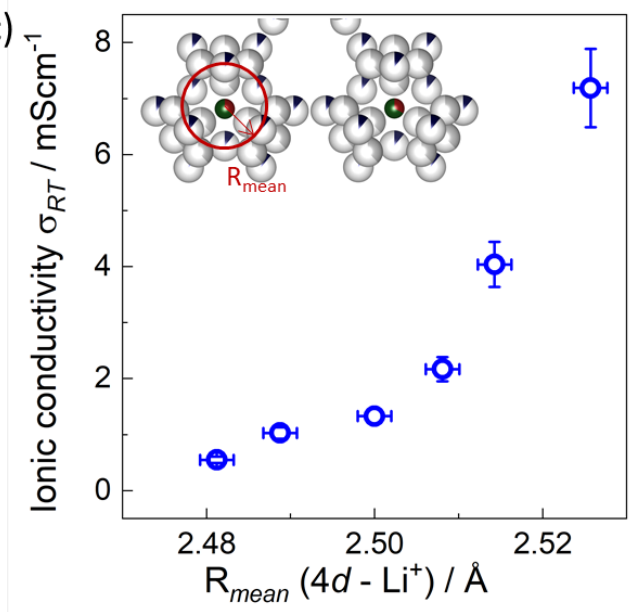

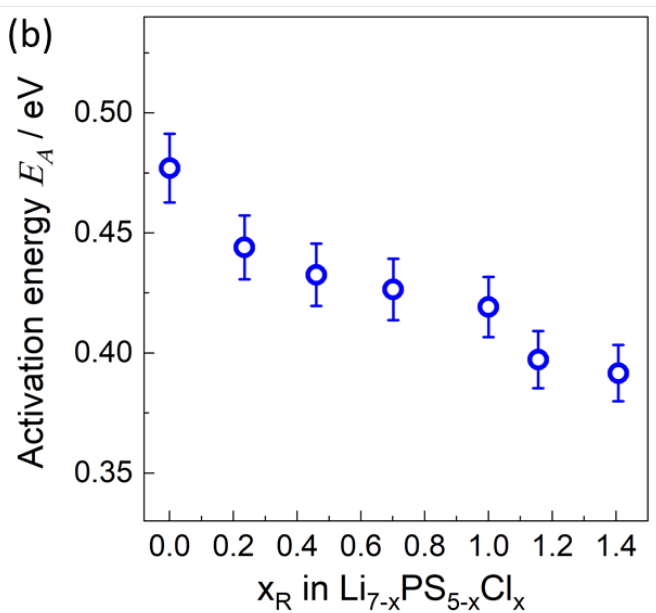

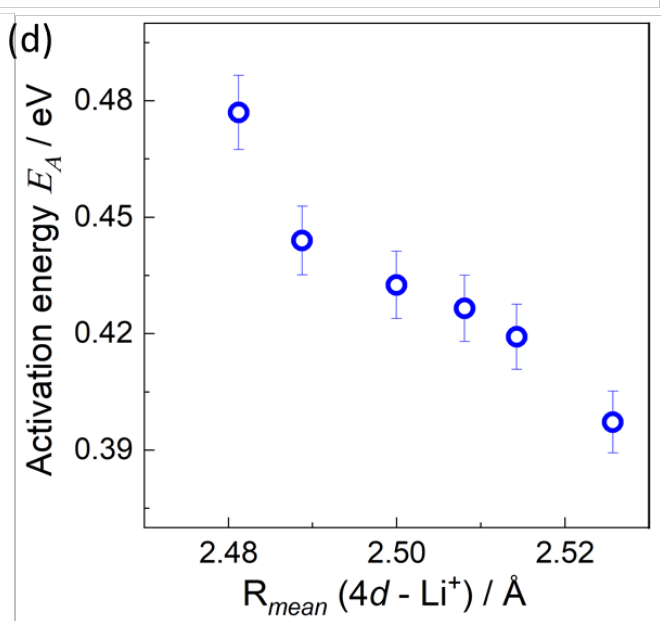

Figure 5: a) Room-temperature ionic conductivity and b) activation energies of $\mathrm{Li}_{7-x} P S_{6-x} \mathrm{Cl}_{x}$ as a function of the refined chloride composition. c) Room-temperature ionic conductivity and (d) activation energy as a function of $R_{\text {mean }}$.

The room temperature ionic conductivities and corresponding activation energies are shown in Figures 5 as a function of the refined chloride content. The ionic conductivity increases from 0.55 $\mathrm{mScm}^{-1}$ at $\mathrm{x}_{\mathrm{R}}=0.235$ to $7.2 \mathrm{mScm}^{-1}$ at $\mathrm{x}_{\mathrm{R}}=1.40$, along with a concomitant decrease in activation energy from 0.48 to $0.39 \mathrm{eV}$, respectively. These obtained values are similar to the recent work on 
the substitution series $\mathrm{Li}_{6-\mathrm{x}} \mathrm{PS}_{5-\mathrm{x}} \mathrm{Cl}_{1+\mathrm{x}}$, which achieved a conductivity of over $9 \mathrm{mScm}^{-1}$ and activation energy of $0.29 \mathrm{eV}$ at $x=0.5 .{ }^{33}$ Small differences in conductivities between these same compositions likely arise from measurement practices across working groups. ${ }^{16}$ Figure $5 \mathrm{c}$ shows the ionic conductivity as a function of $R_{\text {mean. }}$. The conductivity increases with $R_{\text {mean, }}$, from a value of $0.55 \mathrm{mS} \mathrm{cm}{ }^{-1}(2.475 \AA)$ to $7.2 \mathrm{mScm}^{-1}(2.525 \AA)$. This is expected as higher $R_{\text {mean }}$ means a higher level of interconnectivity of the cages, easing Li movement through the structure. ${ }^{26,29}$ Figure $5 \mathrm{~d}$ show that the activation energy decreases as a function of $R_{\text {mean. Interestingly, the increase in }}$ conductivity is not linear, instead exhibiting a drastic increase after $x=1.00$. This behavior is not reflected as much in the activation energy. Clearly something significant happens at $\mathrm{Cl}^{-}$content higher than $\mathrm{Li}_{6} \mathrm{PS}{ }_{5} \mathrm{Cl}(x=1.00)$; whether this has to do with having more $\mathrm{Cl}^{-}$than a single $4 a / 4 d$ site could hold, or reaching a critical lower concentration of $\mathrm{Li}^{+}$per unit cell, or a different cause, is unclear at this time.

(a)
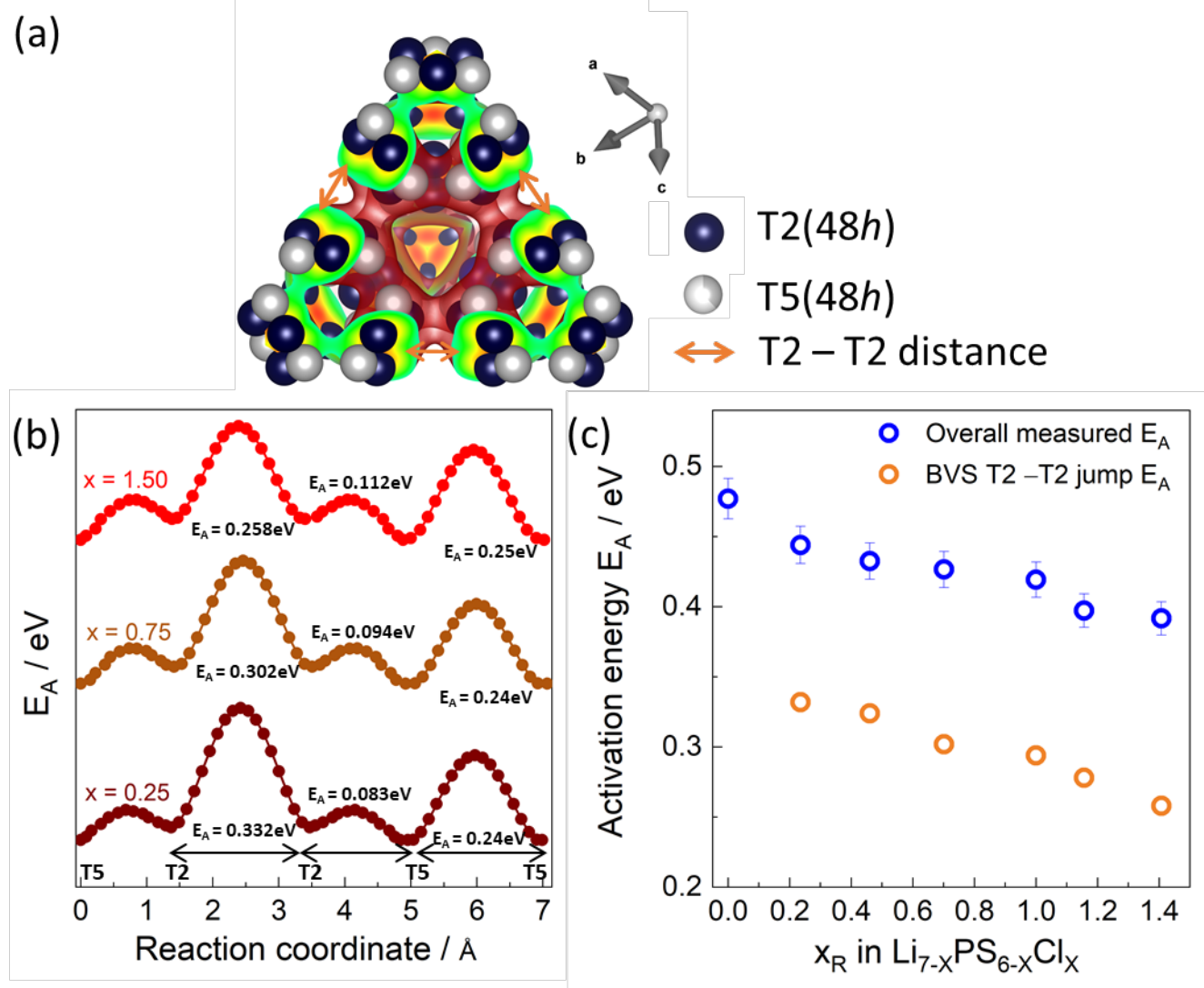

Figure 6: a): The Li-ion migration pathways were analyzed using the bond valence sum method with additional chloride content, showing $T 2-T 2$ jump distance which represent the interconnected cages. b) Migration barrier along the T5 - T2 - T2 - T5 - T5 pathway that 
corresponds to transport from one cage to the next. c) The experimental activation energy, calculated T2 - T2 migration barrier that can be observed with additional chloride content.

In order to gain insight into the energetics of lithium diffusion pathways, we performed bond valence sum analyses. $\mathrm{The}^{+}{ }^{+}$positions and structural framework are determined from the neutron diffraction data. The experimental activation energy is calculated using impedance spectroscopy and obtained T2 - T2 activation energies are extracted from the bond valence sum. Figure $6 \mathrm{a}$ shows a visual representation of cages along with $\mathrm{Li}$-ion migration pathways. $\mathrm{The}^{+} \mathrm{i}^{+}$pathway is chosen along the T2 and T5 sites: T5 - T2 - T2 - T5 - T5 (Figure $6 \mathrm{~b}$ ). As the $\mathrm{Cl}^{-}$content increases in $\mathrm{Li}_{7-\mathrm{x}} \mathrm{PS}_{6_{-} \mathrm{x}} \mathrm{Cl}_{\mathrm{x}}$, the activation energy for a $\mathrm{T} 2-\mathrm{T} 2$ jump decreases and for a $\mathrm{T} 2-\mathrm{T} 5$ jump increases. However, the T2 - T2 jump shows the highest energy barriers, suggesting to be the rate limiting step. These T2 - T2 activation energies are shown together with the experimental activation energies in Figure 6c; the magnitude of the experimental results is higher than predicted, but a similar trend with increasing $\mathrm{Cl}^{-}$content is found. The more interconnected the $\mathrm{Li}^{+}$cages are, corroborated by an expanding $R_{\text {mean }}$ and a decreasing T2 - T2 distance, the lower the activation barriers and better ionic transport properties.

\section{Conclusion}

We have synthesized the chloride enriched lithium argyrodites $\mathrm{Li}_{7-\mathrm{x}} \mathrm{PS}_{6-\mathrm{x}} \mathrm{Cl}_{\mathrm{x}}$ with compositions from $\mathrm{x}_{\mathrm{N}}=0.0$ to $\mathrm{x}_{\mathrm{N}}=1.75$. Neutron powder diffraction was utilized to study the $\mathrm{Li}^{+}$substructure and its effects on the ionic transport. With increasing $\mathrm{Cl}^{-}$content, the $\mathrm{Li}^{+}$"cages" expand, indicated in both decreases of T2 - T2 site distances and, in a more general sense, increases in the radial distribution of $\mathrm{Li}^{+}$away from the center of the cage, characterized by $R_{\text {mean }}$. The changing average anionic charge distribution by $\mathrm{Cl}^{-}$addition has a strong effect on $R_{\text {mean }}$ and ultimately the conductivity as it leads to a much better connected $\mathrm{Li}^{+}$landscape. This work offers a common thread to previous studies showing that, while disorder and composition play a role in increasing conductivity, one of the underlying concepts is the importance of the anionic charge distribution and how much the $\mathrm{Li}^{+}$substructure is interconnected. Fully understanding how the substructure is impacted by chemical changes is a key to tailoring transport properties, and this general methodology should be applicable to many other superionic conductors. 


\section{Supporting Information}

All refined neutron powder diffraction data of the chloride enriched lithium argyrodites $\mathrm{Li}_{7-\mathrm{x}} \mathrm{PS}_{6-\mathrm{x}} \mathrm{Cl}_{\mathrm{x}}$ series are reported here, as well as additional information on the constraints applied during the refinements and the refinement results. Further shown are the X-ray diffraction data of $\mathrm{Li}_{7} \mathrm{PS}_{6}$ All impedance spectra are provided. Crystallographic information files (CIF) are also provided.

\section{Acknowledgments}

The research was supported by the Federal Ministry of Education and Research (BMBF) within the project FESTBATT under grant number 03XP0177A. The D2B high-resolution diffractometer and monochromatic neutron source was used for measurement of neutron diffraction, operated by the Institut Laue-Langevin, Grenoble, France.

\section{Conflict of Interest}

The authors declare no competing financial interests.

\section{References}

(1) Randau, S.; Weber, D. A.; Kötz, O.; Koerver, R.; Braun, P.; Weber, A.; Ivers-Tiffée, E.; Adermann, T.; Kulisch, J.; Zeier, W. G.; Richter, F. H.; Janek, J. Benchmarking the Performance of All-Solid-State Lithium Batteries. Nat. Energy 2020, 5 , 259-270.

(2) Lee, Y. G.; Fujiki, S.; Jung, C.; Suzuki, N.; Yashiro, N.; Omoda, R.; Ko, D. S.; Shiratsuchi, T.; Sugimoto, T.; Ryu, S.; Ku, J. H.; Watanabe, T.; Park, Y.; Aihara, Y.; Im, D.; Han, I. T. High-Energy Long-Cycling All-Solid-State Lithium Metal Batteries Enabled by SilverCarbon Composite Anodes. Nat. Energy 2020, 5, 299-308.

(3) Janek, J.; Zeier, W. G. A Solid Future for Battery Development. Nat. Energy 2016, 16141.

(4) Kato, Y.; Hori, S.; Saito, T.; Suzuki, K.; Hirayama, M.; Mitsui, A.; Yonemura, M.; Iba, H.; Kanno, R. High-Power All-Solid-State Batteries Using Sulfide Superionic Conductors. Nat. Energy 2016, 1, 1-7.

(5) Auvergniot, J.; Cassel, A.; Ledeuil, J. B.; Viallet, V.; Seznec, V.; Dedryvère, R. Interface Stability of Argyrodite $\mathrm{Li}_{6} \mathrm{PS}_{5} \mathrm{Cl}$ toward $\mathrm{LiCoO}_{2}, \mathrm{LiNi}_{1 / 3} \mathrm{Co}_{1 / 3} \mathrm{Mn}_{1 / 3} \mathrm{O}_{2}$, and $\mathrm{LiMn}_{2} \mathrm{O}_{4}$ in 
Bulk All-Solid-State Batteries. Chem. Mater. 2017, 29, 3883-3890.

(6) Liu, Q.; Geng, Z.; Han, C.; Fu, Y.; Li, S.; He, Y.; Kang, F. Challenges and Perspectives of Garnet Solid Electrolytes for All Solid-State Lithium Batteries. J. Power Sources 2018, 389 , 120-134.

(7) Song, Y.; Yang, L.; Zhao, W.; Wang, Z.; Zhao, Y.; Wang, Z.; Wang Q.; Liu H.; Pan F Revealing the Short-Circuiting Mechanism of Garnet-Based Solid-State Electrolyte. Adv. Energy Mater. 2019, 9, 1900671.

(8) Yoshinari, T.; Koerver, R.; Hofmann, P.; Uchimoto, Y.; Zeier, W. G.; Janek, J. Interfacial Stability of Phosphate-NASICON Solid Electrolytes in Ni- Rich NCM Cathode-Based Solid-State Batteries. ACS Appl. Mater. Interfaces 2019, 11, 23244-23253.

(9) Yu, S.; Mertens, A.; Tempel, H.; Schierholz, R.; Kungl, H.; Eichel, R. Monolithic AllPhosphate Solid-State Lithium-Ion Battery with Improved Interfacial Compatibility. ACS Appl. Mater. Interfaces 2018, 10, 22264-22277.

(10) Asano, T.; Sakai, A.; Ouchi, S.; Sakaida, M.; Miyazaki, A. Solid Halide Electrolytes with High Lithium-Ion Conductivity for Application in 4 V Class Bulk-Type All-Solid-State Batteries. Adv. Energy Mater. 2018, 30, 1803075.

(11) Park, K.; Kaup, K.; Assoud, A.; Zhang, Q.; Wu, X.; Nazar, L. F. High-Voltage Superionic Halide Solid Electrolytes for All-Solid-State Li-Ion Batteries. ACS Energy Lett. 2020, 5, 2, 533-539.

(12) Riegger, L. M.; Schlem, R.; Sann, J.; Zeier, W. G.; Janek, J. Lithium-Metal Anode Instability of the Superionic Halide Solid Electrolytes and the Implications for Solid-State Batteries. Angew. Chemie 2021, 133, 6792-6797.

(13) Schlem, R.; Muy, S.; Prinz, N.; Banik, A.; Shao-Horn, Y.; Zobel, M.; Zeier, W. G. Mechanochemical Synthesis: A Tool to Tune Cation Site Disorder and Ionic Transport Properties of $\mathrm{Li}_{3} \mathrm{MCl}_{6}(\mathrm{M}=\mathrm{Y}, \mathrm{Er})$ Superionic Conductors. Adv. Energy Mater. 2020, 10, 1903719.

(14) Hanghofer, I.; Gadermaier, B.; Wilkening, H. M. R. Fast Rotational Dynamics in Argyrodite-Type $\mathrm{Li}_{6} \mathrm{PS}_{5} \mathrm{X}(\mathrm{X}: \mathrm{Cl}, \mathrm{Br}, \mathrm{I})$ as Seen by ${ }^{31} \mathrm{P}$ Nuclear Magnetic Relaxation - On Cation-Anion Coupled Transport in Thiophosphates. Chem. Mater. 2019, 31, 4591-4597.

(15) Ohno, S.; Banik, A.; Dewald, G. F.; Kraft, M. A.; Krauskopf, T.; Minafra, N.; Till, P.; Weiss, M.; Zeier, W. G. Materials Design of Ionic Conductors for Solid State Batteries. 
Prog. Energy 2020, 2, 022001.

(16) Ohno, S.; Bernges, T.; Buchheim, J.; Duchardt, M.; Hatz, A. K.; Kraft, M. A.; Kwak, H.; Santhosha, A. L.; Liu, Z.; Minafra, N.; Tsuji, F.; Sakuda, A.; Schlem, R.; Xiong, S.; Zhang, Z.; Adelhelm, P.; Chen, H.; Hayashi, A.; Jung, Y. S.; Lotsch, B. V.; Roling, B.; VargasBarbosa, N. M.; Zeier, W. G. How Certain Are the Reported Ionic Conductivities of Thiophosphate-Based Solid Electrolytes? An Interlaboratory Study. ACS Energy Lett. 2020, 5, 910-915.

(17) Yu, C.; Hageman, J.; Ganapathy, S.; Van Eijck, L.; Zhang, L.; Adair, K. R.; Sun, X.; Wagemaker, M. Tailoring $\mathrm{Li}_{6} \mathrm{PS}_{5} \mathrm{Br}$ Ionic Conductivity and Understanding of Its Role in Cathode Mixtures for High Performance All-Solid-State Li-S Batteries. J. Mater. Chem. A 2019, 7, 10412-10421.

(18) Kasemchainan, J.; Zekoll, S.; Spencer Jolly, D.; Ning, Z.; Hartley, G. O.; Marrow, J.; Bruce, P. G. Critical Stripping Current Leads to Dendrite Formation on Plating in Lithium Anode Solid Electrolyte Cells. Nat. Mater. 2019, 18, 1105-1111.

(19) Kraft, M. A.; Culver, S. P.; Calderon, M.; Böcher, F.; Krauskopf, T.; Senyshyn, A.; Dietrich, C.; Zevalkink, A.; Janek, J.; Zeier, W. G. Influence of Lattice Polarizability on the Ionic Conductivity in the Lithium Superionic Argyrodites $\mathrm{Li}_{6} \mathrm{PS}_{5} \mathrm{X}(\mathrm{X}=\mathrm{Cl}$, Br, I). J. Am. Chem. Soc. 2017, 139, 10909-10918.

(20) Wang, H.; Yu, C.; Ganapathy, S.; van Eck, E. R. H.; van Eijck, L.; Wagemaker, M. A Lithium Argyrodite $\mathrm{Li}_{6} \mathrm{PS}_{5} \mathrm{Cl}_{0.5} \mathrm{Br}_{0.5}$ Electrolyte with Improved Bulk and Interfacial Conductivity. J. Power Sources 2019, 412, 29-36.

(21) Patel, S. V; Banerjee, S.; Liu, H.; Wang, P.; Chien, P.; Feng, X.; Liu, J.; Ong, S. P.; Hu, Y. Tunable Lithium-Ion Transport in Mixed-Halide Argyrodites $\mathrm{Li}_{6-\mathrm{x}} \mathrm{PS}_{5-\mathrm{x}} \mathrm{ClBr}_{\mathrm{x}}$ : An Unusual Compositional Space Chem. Mater. 2021, 33, 4, 1435-1443.

(22) Bernges, T.; Culver, S. P.; Minafra, N. N.; Koerver, R.; Zeier, W. G. Competing Structural Influences in the Li Superionic Conducting Argyrodites $\mathrm{Li}_{6} \mathrm{PS}_{5-\mathrm{x}} \mathrm{Se} \mathrm{x}_{\mathrm{x}} \mathrm{Br}(0 \leq \mathrm{x} \leq 1)$ upon Se Substitution. Inorg. Chem. 2018, 57, 13920-13928.

(23) Zhao, F.; Liang, J.; Yu, C.; Sun, Q.; Li, X.; Adair, K.; Wang, C.; Zhao, Y.; Zhang, S.; Li, W.; Deng, S.; Li, R.; Huang, Y.; Huang, H.; Zhang, L.; Zhao, S.; Lu, S.; Sun, X. A Versatile Sn-Substituted Argyrodite Sulfide Electrolyte for All-Solid-State Li Metal Batteries. $A d v$. Energy Mater. 2020, 10, 1903422.. 
(24) Kraft, M. A.; Ohno, S.; Zinkevich, T.; Koerver, R.; Culver, S. P.; Senyshyn, A.; Indris, S.; Morgan, B. J.; Zeier, W. G. Inducing High Ionic Conductivity in the Lithium Superionic Argyrodites $\mathrm{Li}_{6+\mathrm{x}} \mathrm{P}_{1-\mathrm{x}} \mathrm{Ge}_{\mathrm{x}} \mathrm{S}_{5} \mathrm{I}$ for All-Solid-State Batteries. J. Am. Chem. Soc. 2018, 140 , 16330-16339.

(25) Ohno, S.; Helm, B.; Fuchs, T.; Dewald, G.; Kraft, M. A.; Culver, S. P.; Senyshyn, A.; Zeier, W. G. Further Evidence for Energy Landscape Flattening in the Superionic Argyrodites Li ${ }_{6+}$ ${ }_{\mathrm{x}} \mathrm{P}_{1-\mathrm{x}} \mathrm{M}_{\mathrm{x}} \mathrm{S}_{5} \mathrm{I}(\mathrm{M}=\mathrm{Si}, \mathrm{Ge}, \mathrm{Sn})$. Chem. Mater. 2019, 31, 4936-4944.

(26) Minafra, N.; Kraft, M. A.; Bernges, T.; Li, C.; Schlem, R.; Morgan, B. J.; Zeier, W. G. Local Charge Inhomogeneity and Lithium Distribution in The Superionic Argyrodites $\mathrm{Li}_{6} \mathrm{PS}_{5} \mathrm{X}(\mathrm{X}=\mathrm{Cl}$, Br, I ). Inorg. Chem. 2020, 59, 15, 11009-11019.

(27) Kong, S. T.; Deiseroth, H. J.; Reiner, C.; Guen, O.; Neumann, E.; Ritter, C.; Zahn, D. Lithium Argyrodites with Phosphorus and Arsenic : Order and Disorder Of. Lithium Atoms, Crystal Chemistry, Phase Transitions. Chem. Eur. J. 2010, 16, 2198 - 2206.

(28) Deiseroth, H.; Maier, J.; Weichert, K.; Nickel, V.; Kong, S.; Reiner, C. Li $7 \mathrm{PS}_{6}$ and $\mathrm{Li}_{6} \mathrm{PS}_{5}$ $\mathrm{X}(\mathrm{X}=\mathrm{Cl}, \mathrm{Br}, \mathrm{I})$ : Possible Three-Dimensional Diffusion Pathways for Lithium Ions and Temperature Dependence of the Ionic Conductivity by Impedance Measurements. Z. Anorg. Allg. Chem. 2011, 637, 1287-1294.

(29) Gautam, A.; Sadowski, M.; Ghidiu, M.; Minafra, N.; Senyshyn, A.; Albe, K.; Zeier, W. G. Engineering the Site-Disorder and Lithium Distribution in the Lithium Superionic Argyrodite $\mathrm{Li}_{6} \mathrm{PS}_{5} \mathrm{Br}$. Adv. Energy Mater. 2021, 11, 2003369.

(30) Morgan, B. J. Mechanistic Origin of Superionic Lithium Diffusion in Anion- Disordered Li ${ }_{6} \mathrm{PS}_{5} \mathrm{X}$ Argyrodites. Chem. Mater. 2021, 33, 6, 2004-2018.

(31) Gautam, A.; Sadowski, M.; Prinz, N.; Eickhoff, H.; Minafra, N.; Ghidiu, M.; Culver, S. P. S. P.; Albe, K.; Fässler, T. F. T. F.; Zobel, M.; Zeier, W. G. W. G. Rapid Crystallization and Kinetic Freezing of Site-Disorder in the Lithium Superionic Argyrodite $\mathrm{Li}_{6} \mathrm{PS}_{5} \mathrm{Br}$. Chem. Mater. 2019, 31, 10178-10185.

(32) Zhou, L.; Assoud, A.; Zhang, Q.; Wu, X.; Nazar, L. F. New Family of Argyrodite Thioantimonate Lithium Superionic Conductors. J. Am. Chem. Soc. 2019, 141, 1900219013.

(33) Adeli, P.; Bazak, J. D.; Park, K. H.; Kochetkov, I.; Huq, A.; Goward, G. R.; Nazar, L. F. Boosting Solid-State Diffusivity and Conductivity in Lithium Superionic Argyrodites by 
Halide Substitution. Angew. Chem. Int. Ed. 2019, 58, $8681-8686$.

(34) Wang, P.; Liu, H.; Patel, S.; Feng, X.; Chien, P.; Wang, Y.; Hu, Y. Fast Ion Conduction and Its Origin in $\mathrm{Li}_{6-\mathrm{x}} \mathrm{PS}_{5-\mathrm{x}} \mathrm{Br}_{1+\mathrm{x}}$. Chem. Mater. 2020, 32, 9, 3833-3840

(35) Adams, S. Bond Valence Analysis of Structure - Property Relationships in Solid Electrolytes. Journal of Power Sources 159 ,2006, 200-204.

(36) Zhang, W.; Weber, D. A.; Weigand, H.; Arlt, T.; Manke, I.; Der, D. S.; Koerver, R.; Leichtweiss, T.; Hartmann, P.; Zeier, W. G.; Janek, J. Interfacial Processes and Influence of Composite Cathode Microstructure Controlling the Performance of All-Solid-State Lithium Batteries. ACS Appl. Mater. Interfaces 2017, 9, 21, 17835-17845. 
For Table of Contents only

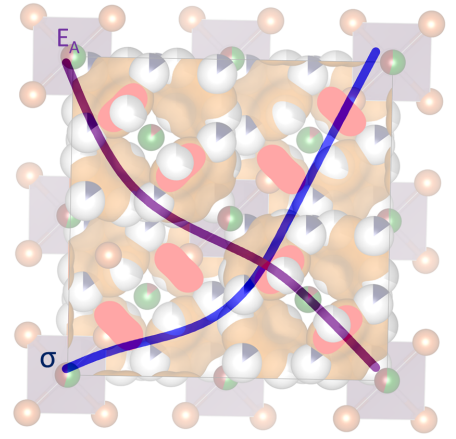

